\title{
Development of Low-Noise Small-Area 24 GHz CMOS Radar Sensor
}

\author{
Min Yoon ${ }^{1}$ and Jee-Youl Ryu ${ }^{2}$ \\ ${ }^{1}$ Department of Statistics, Pukyong National University, Busan 48513, Republic of Korea \\ ${ }^{2}$ Department of Information and Communications Engineering, Pukyong National University, Busan 48513, Republic of Korea
}

Correspondence should be addressed to Jee-Youl Ryu; ryujy@pknu.ac.kr

Received 9 March 2016; Revised 6 June 2016; Accepted 30 June 2016

Academic Editor: Jesus Corres

Copyright (C) 2016 M. Yoon and J.-Y. Ryu. This is an open access article distributed under the Creative Commons Attribution License, which permits unrestricted use, distribution, and reproduction in any medium, provided the original work is properly cited.

\begin{abstract}
We present a low-noise small-area $24 \mathrm{GHz}$ CMOS radar sensor for automotive collision avoidance. This sensor is based on directconversion pulsed-radar architecture. The proposed circuit is implemented using TSMC $0.13 \mu \mathrm{m}$ RF (radio frequency) CMOS $\left(f_{T} / f_{\max }=120 / 140 \mathrm{GHz}\right)$ technology, and it is powered by a $1.5 \mathrm{~V}$ supply. This circuit uses transmission lines to reduce total chip size instead of real bulky inductors for input and output impedance matching. The layout techniques for RF are used to reduce parasitic capacitance at the band of $24 \mathrm{GHz}$. The proposed sensor has low cost and low power dissipation since it is realized using CMOS process. The proposed sensor showed the lowest noise figure of $2.9 \mathrm{~dB}$ and the highest conversion gain of $40.2 \mathrm{~dB}$ as compared to recently reported research results. It also showed small chip size of $0.56 \mathrm{~mm}^{2}$, low power dissipation of $39.5 \mathrm{~mW}$, and wide operating temperature range of -40 to $+125^{\circ} \mathrm{C}$.
\end{abstract}

\section{Introduction}

The rapid evolution of wireless communications has resulted in a strong motivation toward building high performance SoC (System-on-a-Chip) in silicon. Particularly CMOSbased circuit is realizing its low cost and high level of integration. Thanks to these advantages, the growing demand for larger bandwidth also pursues CMOS-based circuits to move toward higher frequencies [1-4]. Recent works have shown these circuits as a promising technology for building high performance RF (radio frequency) circuits for applications above $20 \mathrm{GHz}$ [5-8]. These systems for applications of above $20 \mathrm{GHz}$ contain wireless sensor networks, various portable products, automotive collision avoidance radars, wireless local networks, LMDS (local multipoint distribution service), RTIS (Real Time Traffic Information System), and other ISM band applications. Most of all, automotive collision avoidance radar using $24 \mathrm{GHz}$ band offers safety functions such as precrash sensing and collision. Most of the wellknown car companies and suppliers are already working on the development of the next generation vehicle known as ASV (Advanced Safety Vehicle). The radar-based ACC (autonomous cruise control) at $77 \mathrm{GHz}$ first introduced from Mercedes-Benz in 1999 is widely available in many high and mid class automotive models. In the last 15 years, silicon-based $24 \mathrm{GHz}$ short-range automotive radars have been investigated by both industry and academia $[5,6]$. Therefore, next generation radars may well be required to support $24 \mathrm{GHz}$ band for compatibility and lower overall cost [5-9].

In this paper, we propose a low-noise and small-area $24 \mathrm{GHz}$ receiver for the automotive radar. The proposed circuit is fabricated using TSMC $0.13 \mu \mathrm{m} \operatorname{RF}$ CMOS $\left(f_{T} / f_{\max }=\right.$ $120 / 140 \mathrm{GHz}$ ) technology. The circuit is powered by a $1.5 \mathrm{~V}$ supply. It is designed using a direct-conversion scheme to simplify overall system complexity. Especially to reduce total chip size instead of real bulky inductors, transmission lines are used. We used the unique layout technique for $24 \mathrm{GHz}$ $\mathrm{RF}$ band to reduce parasitic capacitance.

\section{Radar Sensor Principle}

Thanks to the higher positioning accuracy and its narrow bandwidth, frequency-modulated continuous wave (FMCW) 


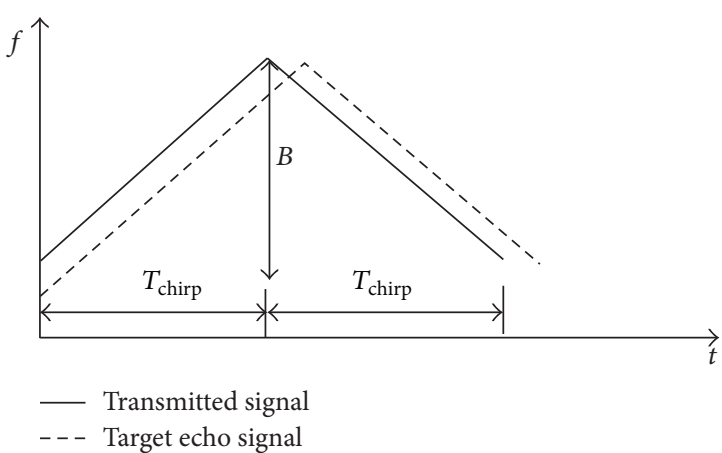

(a)

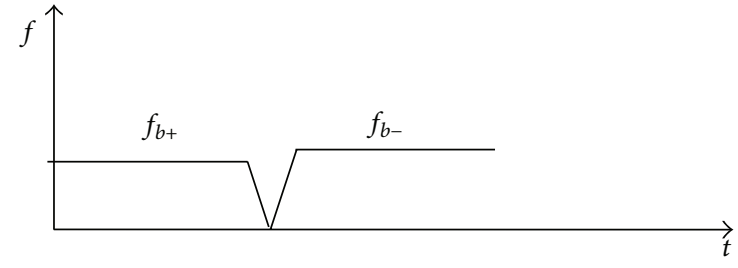

(b)

FIGURE 1: FMCW radar principle.

radar based on positioning techniques is often used in automotive radar systems [5]. The FMCW signal is a classical and well-known waveform for many different radar applications [7]. Generally the system bandwidth is described by $B$ and the chirp duration is named $T_{\text {chirp }}$ for up chirp and down chirp as shown in Figure 1(a). When the signal is transmitted, the radar echo signal is directly downconverted by the instantaneous carrier frequencies, $f_{b+}$ and $f_{b-}$. These are the beat frequencies of up chirp and down chirp, respectively, as shown in Figure 1(b) [7].

For these cases related equations are expressed as (1) [7]. Consider

$$
\begin{aligned}
f_{b+} & =\frac{2 R B}{c T_{\text {chirp }}}-f_{d} \\
f_{b-} & =\frac{2 R B}{c T_{\text {chirp }}}+f_{d} \\
f_{d} & =\frac{2 v}{\lambda},
\end{aligned}
$$

where $R$ is the target range, $c$ is the speed of light, $f_{d}$ is the Doppler frequency produced by moving target, and $\lambda$ is the wavelength of the carrier frequency. From (1), we can obtain the target range $R$ and the radial velocity $v$ by the following equations:

$$
\begin{aligned}
& R=\frac{\left(f_{b+}+f_{b-}\right) c T_{\text {chirp }}}{4 B} \\
& v=\frac{\left(f_{b+}-f_{b-}\right) c T_{\text {chirp }}}{4} \lambda .
\end{aligned}
$$

If there is another radar operation with the same modulation scheme and the same frequency band, mutual interference will occur.

\section{The Proposed Radar Sensor}

3.1. The Proposed Radar Sensor. The proposed sensor is based on the direct-conversion pulsed-radar architecture shown in
Figure 2. The radar senses RF pulses at a rate determined by the prf (pulse repetition frequency). The presence of an object is detected in $R_{x}$ by correlating the reflected pulse with a delayed version of the transmitted pulse. To detect targets over a wide range of 0.1 to $50 \mathrm{~m}$, it is necessary to have a widely tunable delay between pulse transmission and sensor correlation. Most of all, to obtain longer range and higher range resolution, it is necessary to incorporate variable prf and pulse width [8]. To meet these requirements, the CMOS baseband pulse generator shown in Figure 2 can generate pulses with widths ranging from 100 ps to $1 \mathrm{~ns}$ ( $p w[5: 0])$, with a variable $\operatorname{prf}$ of $1 \mathrm{MHz}$ to $1 \mathrm{GHz}(\operatorname{prf}[12: 0])$. The delay of $R_{x}$ trigger can be tuned from $1 \mathrm{~ns}$ to $0.2 \mu \mathrm{s}$ (delay[12:0]), corresponding to the 0.1 to $50 \mathrm{~m}$ radar range. $50 \mathrm{~m}$ might be sufficient for speed below $100 \mathrm{~km} / \mathrm{h}$. The prf generation circuit is clocked by the $100 \mathrm{MHz}$ reference input of the synthesizer. The $1 \mathrm{GHz}$ clock required for $R_{x}$ trigger generation is derived from a divider output in the PLL. To input the control bits of the pulse generator, an on-chip JTAG TAP interface is used.

\subsection{Each Block Design of the Proposed Radar Sensor}

3.2.1. Low-Noise Amplifier. Figure 3 shows a $24 \mathrm{GHz}$ twostage cascode LNA (Low-Noise Amplifier) with inductive degeneration. It is fabricated using TSMC $0.13 \mu \mathrm{m}$ mixedsignal/RF CMOS process $\left(f_{T} / f_{\max }=120 / 140 \mathrm{GHz}\right)$. The outputs of the second stage are combined into LC filter, so they allow sharing of the downconversion chain of the band. Although only one path is active at a time, an interferer from the other input can desensitize the broadband mixer. This circuit uses transmission lines of $L_{T 1} \sim L_{T 10}$ to reduce total chip size instead of real bulky inductors for input and output impedance matching. It has fully symmetrical differential structure to improve linearity of amplifier and to reduce RF noise and unnecessary ripple variations. Series transmission lines of $L_{T 8}$ and $L_{T 10}$ are inserted to increase voltage gain, and parasitic capacitance from drain nodes of $M_{5}$ and $M_{6}$ are minimized by using oscillation effect. $C_{1}\left(\right.$ or $\left.C_{2}\right), L_{T 1}$ (or $L_{T 2}$ ), and $L_{T 3}$ (or $L_{T 5}$ ) are used to make input impedance matching at the first stage. Values of $C_{3}, C_{4}, L_{T 4}, L_{T 6}$, and 


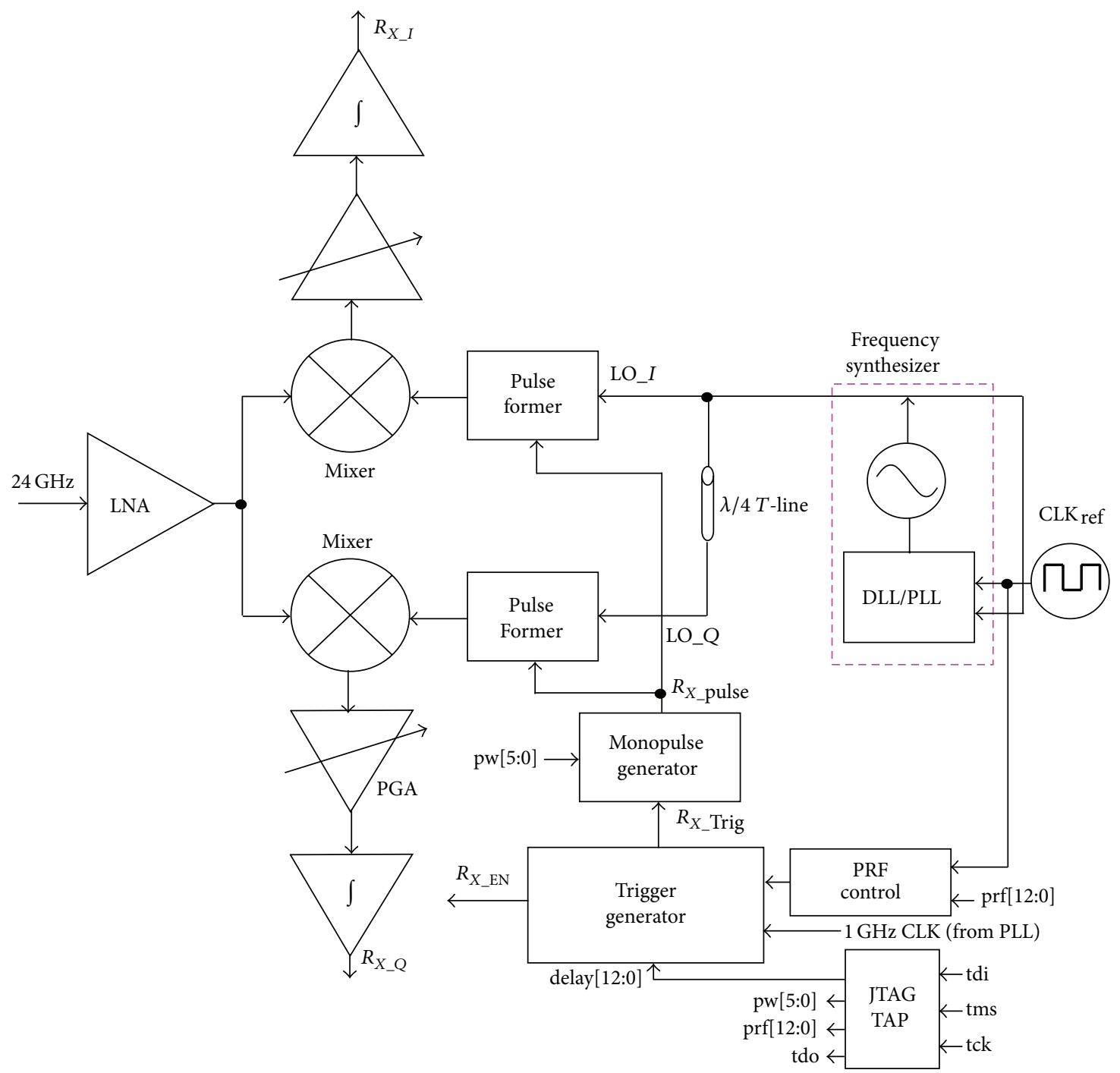

FIGURE 2: The proposed direct-conversion sensor.

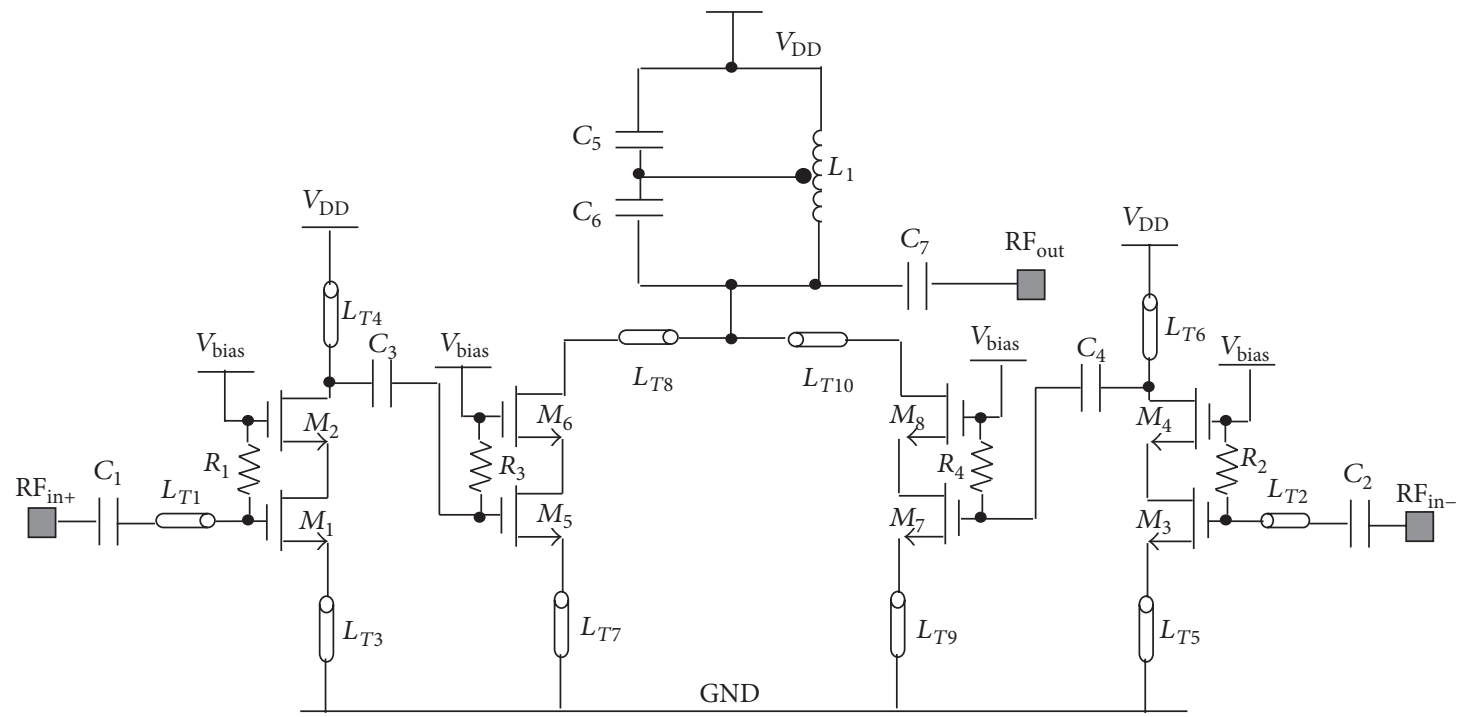

FIGURE 3: Low-noise amplifier for $24 \mathrm{GHz}$ radar sensor. 


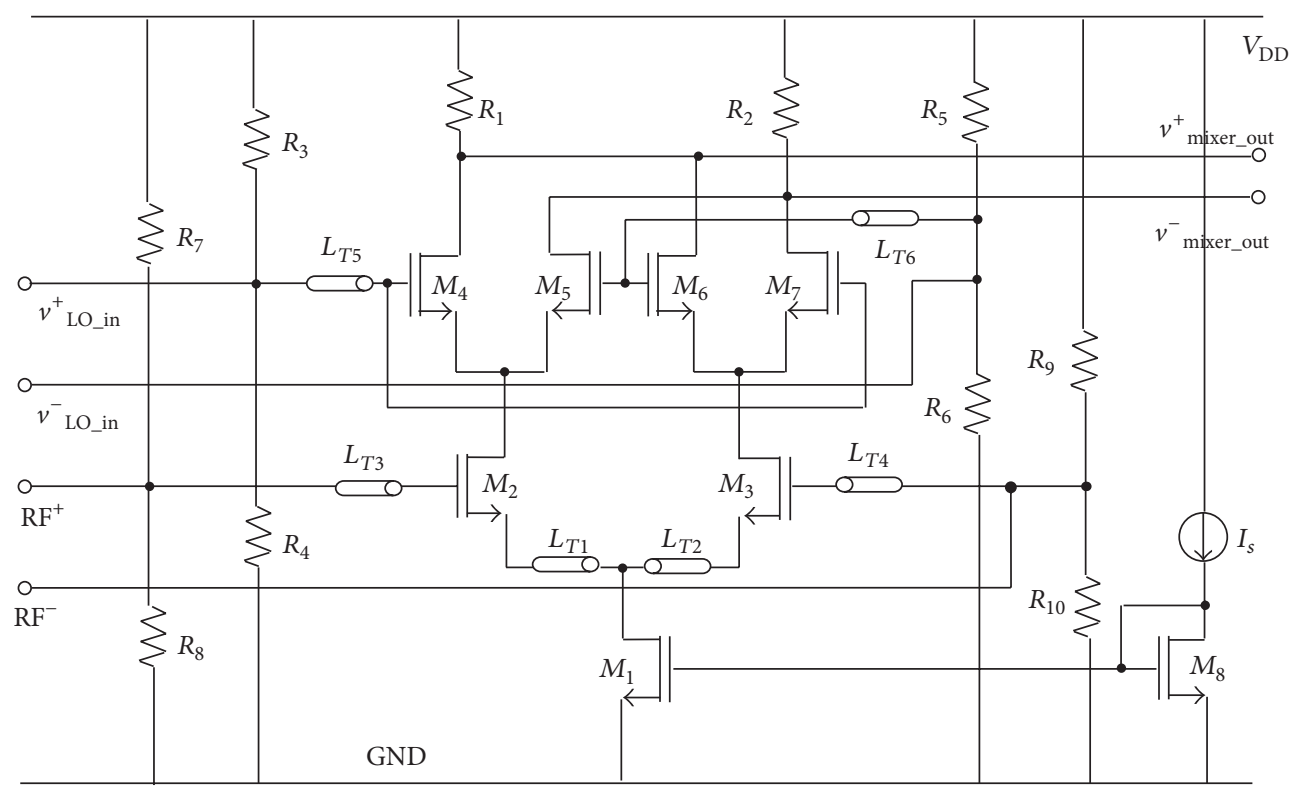

Figure 4: Gilbert-cell downconversion mixer.

$L_{T 7}$ are optimized to make input impedance matching at the second stage. $L_{T 4}$ and $L_{T 6}$ are inserted to supply stable dc in drain regions of $M_{2}$ and $M_{4}$.

The input impedance expressed in (3) is derived using RF small signal equivalent circuit:

$$
Z_{\mathrm{in}(\mathrm{LNA})} \approx \frac{g_{m 1} T_{3}}{C_{g s 1}}+j\left[\omega\left(T_{1}+T_{3}\right)-\frac{1}{\omega C_{g s 1}}\right],
$$

where $C_{g s 1}$ is gate-to-source capacitance of transistor $M_{1}$ and its value is $C_{g s 1}=2 W L C_{o x} / 3+W C_{g s o}$.

Equation (4) is voltage gain derived using $\mathrm{RF}$ small signal equivalent circuit at the first stage, and $C_{3}\left(\right.$ or $\left.C_{4}\right)$ is utilized to control voltage gain:

$$
G_{\mathrm{LNA}}=\frac{T_{4} C_{g s 1}\left(T_{1}+T_{3}\right)}{T_{3}\left[C_{g s 1}\left(T_{1}+T_{3}\right)-C_{3} T_{4}\right]} .
$$

Considering only the drain current noise, the NF (noise figure) of the neutralized LNA can be shown as

$$
F_{1}=1+\frac{\left(Y_{s}^{2}+\omega^{2} C_{g 1}^{2}\right) \gamma g_{d 01} R_{s}}{g_{m 1}^{2}}
$$

where $Y_{s}$ is the source admittance, $R_{s}$ is the source resistance, $\omega$ is the operating angular frequency, $C_{g 1}$ is the gate capacitance, $\gamma$ is the technology-dependent excess noise parameter, and $g_{d 01}$ is the drain-source (channel) conductance at zero drain-source voltage.

In a cascade LNA, the extra common-gate transistor contributes additional noise, resulting in an overall NF of

$$
F_{2}=F_{1}+\frac{\omega^{2}\left(C_{g 1}+C_{g 5}\right)^{2}\left(Y_{s}^{2}+\omega^{2} C_{g 1}^{2}\right) \gamma g_{d 05} R_{s}}{g_{m 1}^{2} g_{m 5}^{2}}
$$

where $C_{g 5}, g_{m 5}$, and $g_{d 05}$ are the corresponding parameters of the cascade transistor.

3.2.2. Downconversion Mixer. The core of the mixer shown in Figure 4 is a double-balanced Gilbert-type mixer. It has also fully symmetrical differential structure to improve linearity of circuit and to reduce RF noise and unnecessary ripple variations. The RF input applies at the gates of $M_{2}$ and $M_{3}$ which are used as transconductance amplifiers. The linearity of these amplifiers is improved by using source degeneration transmission lines $L_{T 1}$ and $L_{T 2}$, which also adjust the input impedance seen looking at the gates of $M_{2}$ and $M_{3}$ to improve the impedance matching at the LNA-mixer interface. $M_{2}$ and $M_{3}$ are biased at $2 \mathrm{~mA}$ dc current.

The chopping function is accomplished by the mixing cells of $M_{4}$ to $M_{7}$, and $1.2 \mathrm{~V}$ peak-to-peak differential LO (local oscillator) signal is applied. Cascode amplifiers following the differential mixing cells are used to drive the $50 \Omega$ loads. The input matching is accomplished by $L_{T 5}$ and $L_{T 6}$.

3.2.3. Voltage-Controlled Oscillator. Figure 5 shows $24 \mathrm{GHz}$ VCO (voltage-controlled oscillator). The proposed circuit is powered by a $1.5 \mathrm{~V}$ supply. This circuit has basic scheme of the switched resonator, and it contains CMOS LC tuning circuit to use a $24 \mathrm{GHz}$ frequency band. It has also fully symmetrical scheme to improve linearity of the circuit and to reduce RF noise and unnecessary ripple variations. The switching transistors $\left(M_{4}\right.$ and $\left.M_{5}\right)$ are designed to operate near the boundary of current-limited and voltage-limited region to reduce power dissipation. In particular, the switched resonator contains the active inductor consisting of transistors $\left(M_{1 a}, M_{2 a}, M_{1 b}\right.$, and $\left.M_{2 b}\right)$ and current sources ( $I_{s 1}$ and $I_{s 2}$ ) instead of real spiral inductor to reduce total chip size and power dissipation. This VCO also contains self-biasing 


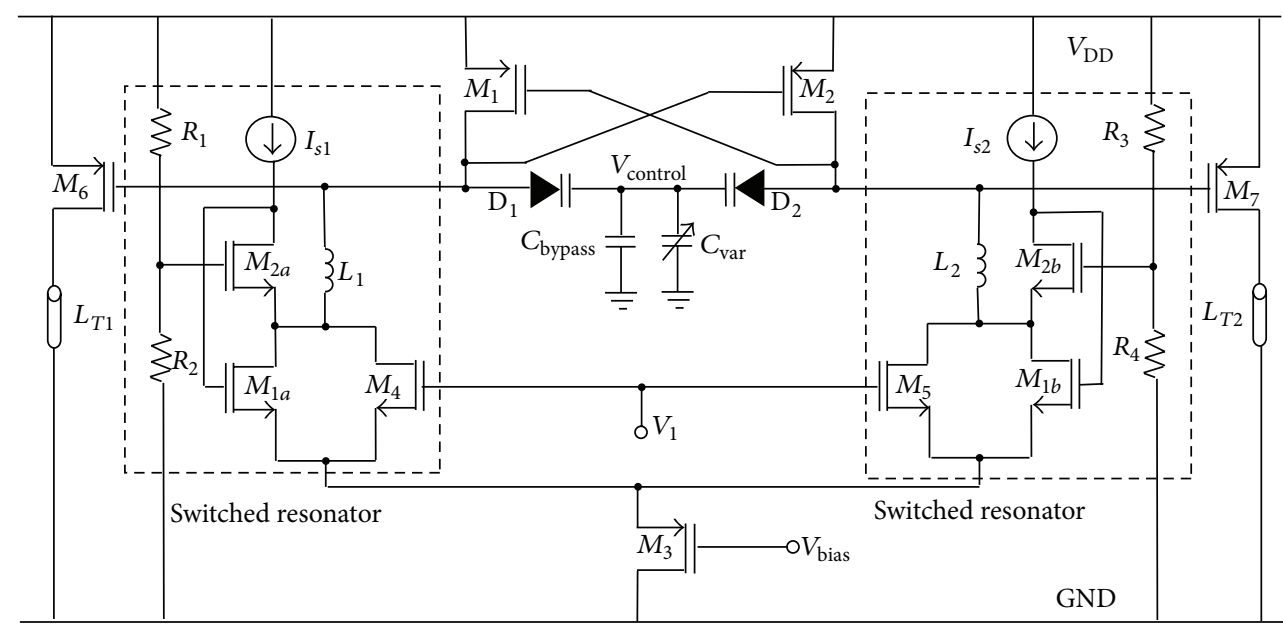

FIGURE 5: Voltage-controlled oscillator.

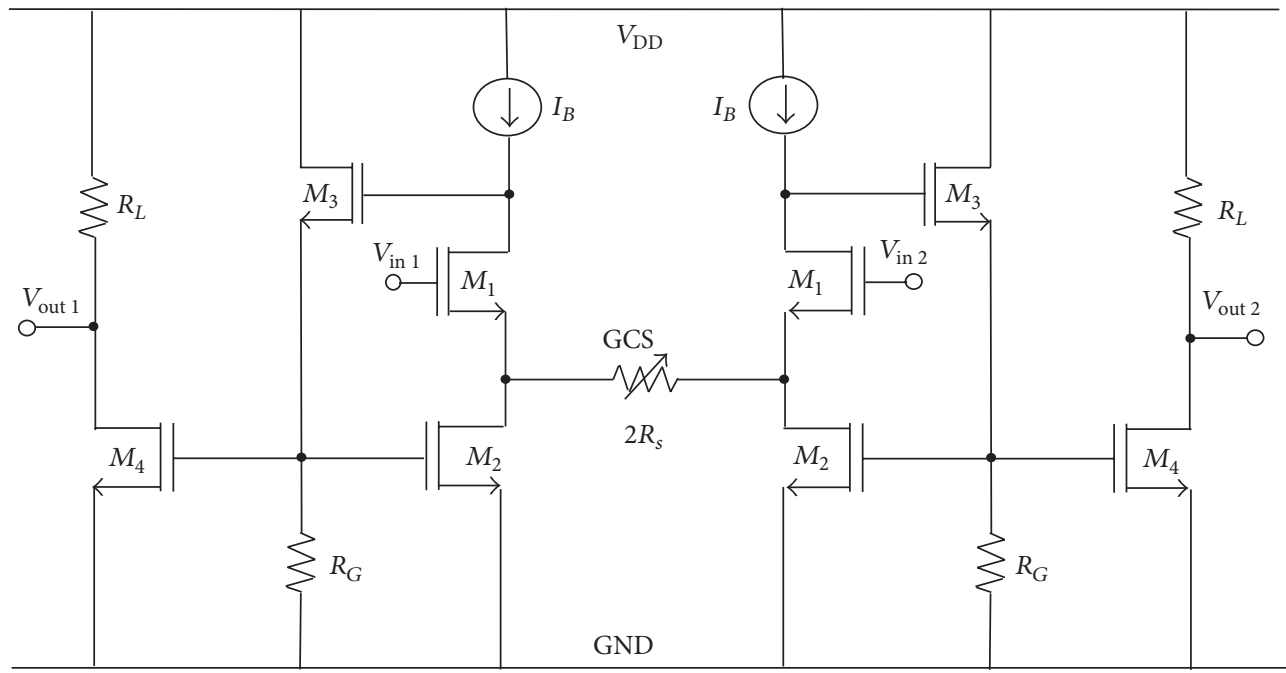

FIgURE 6: Programmable gain amplifier.

control circuits $\left(R_{1} \sim R_{4}\right)$. The notch filtering technique is applied to reduce phase noise from transistor $M_{3}$ for tail current supply.

3.2.4. PGA (Programmable Gain Amplifier). Choosing the method to control a gain is essential at PGA design. The proposed PGA with source degeneration resistor is shown in Figure 6. It has fully symmetrical structure at differential mode, and sources of transistors $M_{1} \sim M_{2}$ have an opposite voltages when two inputs with opposite phases are inserted into the circuit. The amplifier gain can be selected by using a ratio of degeneration or a load resistor. Both sides of the symmetrical structure have the same value with direct current at the source node, and then the gain is adjustable by changing the degeneration resistor $R_{s}$ with GCS (Gain Control Stage). To get higher gain, the value of the total degeneration resistor must be lower, and thus it leads to the increment of gain errors. Therefore, to obtain a more accurate and higher gain, the proposed PGA includes gm-boosted source-degenerated differential pair and an additional amplifier stage. Small signal gain of differential mode is expressed by

$$
\begin{aligned}
& A_{\mathrm{dm}} \\
& =\frac{g_{m 4} g_{m 1} r_{01}\left(r_{04} / / R_{L}\right)}{g_{m 1} g_{m 2} r_{01}\left(r_{02} / / R_{s}\right)+g_{m 2}\left(r_{02} / / R_{s}\right)+1+1 / g_{m 3}\left(r_{03} / / R_{G}\right)},
\end{aligned}
$$

where $r_{0}$ is output resistance.

3.2.5. Switched-Capacitor Integrator. The proposed SC (switched-capacitor) integrator contains some basic building blocks such as operational transconductance amplifier, capacitors, switches, and nonoverlapping clocks as shown in Figure 7. The integrator is implemented in a fully differential configuration to minimize nonidealities such as PSRR, device matching, and noise coupling. The input is sampled during phase $1\left(\phi_{1}\right.$ and $\left.\phi_{1 d}\right)$. During phase 2 , the charge 


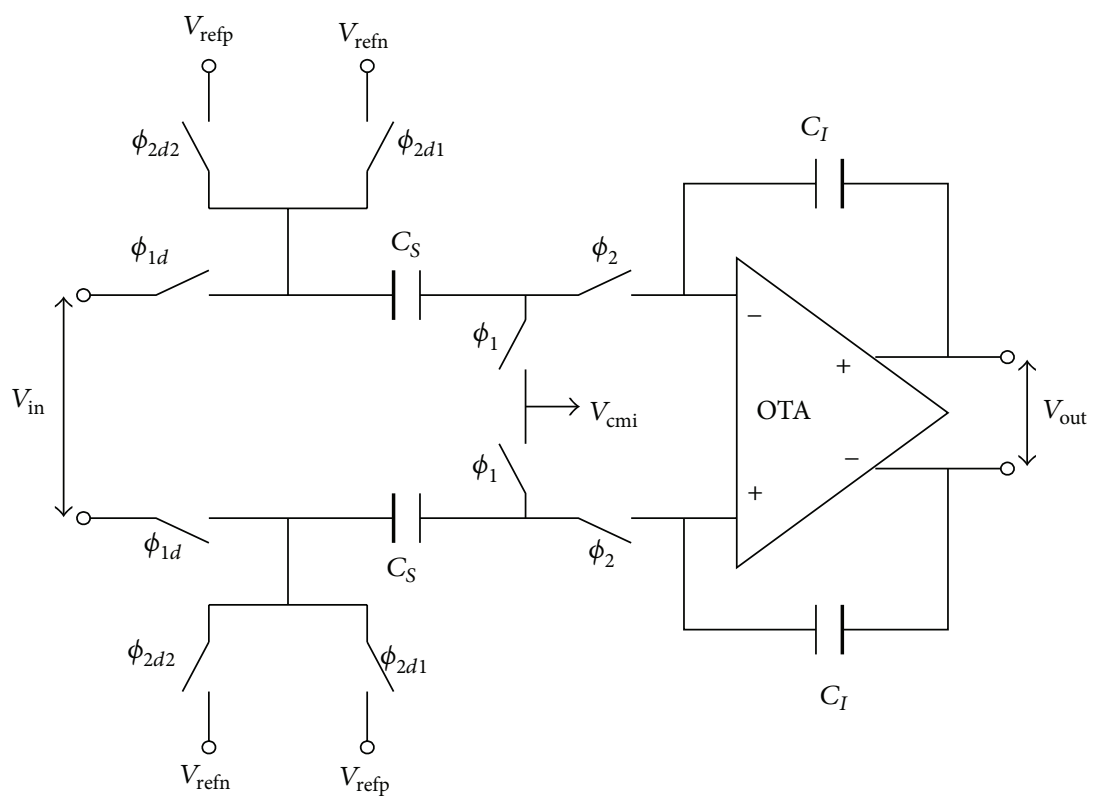

FIGURE 7: Fully differential switched-capacitor integrator.

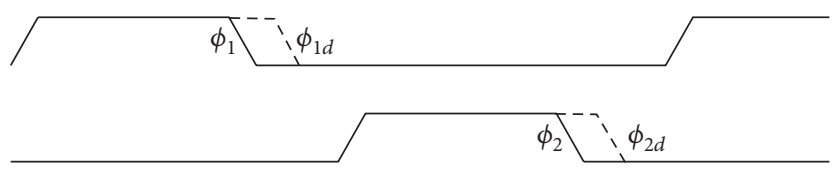

(a)

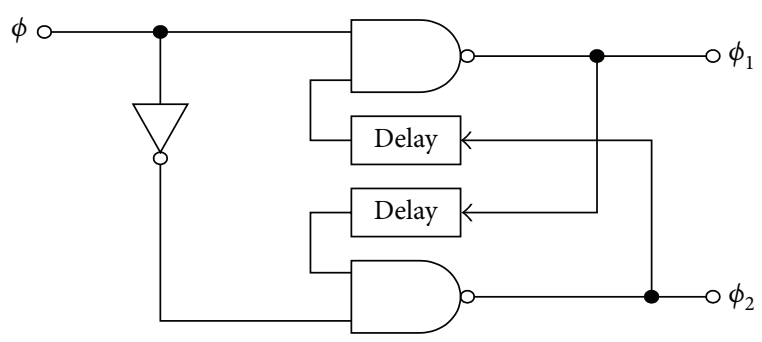

(b)

FIGURE 8: Nonoverlapping clocks: (a) clock signals and (b) possible circuit implementation of nonoverlapping clocks from a single clock.

is transferred from the sampling capacitor, $C_{S}$, to the integrating capacitor, $C_{I}$. At the same time, depending on the output value, the appropriate DAC reference level is applied by closing either labeled switch $\phi_{2 d 1}$ or $\phi_{2 d 2}$. The integrator employs the bottom-plate sampling technique to minimize signal-dependent charge-injection. This is achieved through delayed clocks of $\phi_{1}, \phi_{1 d}$, and $\phi_{2 d}$. When switch $\phi_{1}$ is first turned off, the charge-injection from those switches remains, to a first order, independent of the input signal. Because one of the plates is now floating, turn-off switch $\phi_{1 d}$ shortly does not introduce charge-injection errors.

At least one pair of nonoverlapping clocks is essential in SC circuits. These clocks determine when charge transfers occurs and they must be nonoverlapping to reduce inadvertent charge lost. As seen in Figure 8, the nonoverlapping clocks refer to two logic signals running at the same frequency.

3.2.6. Layout Issues. The circuits are designed and fabricated using TSMC $0.13 \mu \mathrm{m}$ mixed-signal/RF CMOS process $\left(f_{T} / f_{\max }=120 / 140 \mathrm{GHz}\right)$. This process offers six metal layers with two top layers of $0.8 \mu \mathrm{m}$ thick copper. This radar sensor uses transmission lines to reduce total chip size instead of real bulky inductors, and the only inductors $\left(L_{1}\right.$ and $L_{2}$ ) in VCO shown in Figure 5 are spirals. Shield pads are employed at both RF and IF ports. Grounded metall underneath the pads prevents loss of the signal power and noise generation associated with the substrate resistance. Ground rings are placed around each transistor at minimum distance to reduce the substrate loss. To minimize parasitic capacitance all transistors are designed by folded structure $[4,16-19]$. Separated $V_{D D}$ are assigned to the LNA, mixer, VCO, PGA, integrator, and bias circuits. Large on-chip bypass capacitors are placed between each $V_{D D}$ and ground.

Table 1 summarizes each component area for transmission lines of radar sensor. This sensor uses transmission lines to reduce total die size instead of real bulky inductors. The LNA and mixer showed small size of approximately $58 \%$ and $67 \%$ as compared to conventional circuits, respectively. The size of the core cell is only $0.75 \times 0.50 \mathrm{~mm}^{2}$, and the size of chip is $0.80 \times 0.70 \mathrm{~mm}^{2}$ including a large area occupied by the wide ground rings and pads.

The die photograph is shown in Figure 9. The size of the core cell is $0.75 \times 0.50 \mathrm{~mm}^{2}$, and the size of chip is $0.80 \times$ 
TABLE 1: Comparison of each component area of radar sensor.

\begin{tabular}{|c|c|c|c|c|}
\hline & \multicolumn{2}{|c|}{ Proposed circuit } & \multicolumn{2}{|c|}{ Conventional circuit } \\
\hline & Transmission lines & $\begin{array}{c}\text { Area }(W \times L) \\
(\mu \mathrm{m} \times \mu \mathrm{m})\end{array}$ & Inductors & $\begin{array}{c}\text { Area }(W \times L) \\
(\mu \mathrm{m} \times \mu \mathrm{m})\end{array}$ \\
\hline \multirow{5}{*}{ LNA } & $L_{T 1}\left(=L_{T 2}\right)$ & $20 \times 150$ & $L_{1}\left(=L_{2}\right)$ & $70 \times 70$ \\
\hline & $\begin{array}{c}L_{T 3} \\
\left(=L_{T 5}=L_{T 7}=L_{T 9}\right)\end{array}$ & $30 \times 150$ & $L_{3}\left(=L_{5}=L_{7}=L_{9}\right)$ & $80 \times 80$ \\
\hline & $L_{T 8}\left(=L_{T 10}\right)$ & $10 \times 150$ & $L_{8}\left(=L_{10}\right)$ & $50 \times 50$ \\
\hline & Total TL area & $180 \times 150$ & Total inductor area & $\begin{array}{c}140 \times 140+ \\
160 \times 160+ \\
100 \times 100\end{array}$ \\
\hline & Total LNA area & $200 \times 180$ & Total LNA area & $250 \times 250$ \\
\hline \multirow{5}{*}{ Mixer } & $L_{T 1}\left(=L_{T 2}\right)$ & $10 \times 150$ & $L_{1}\left(=L_{2}\right)$ & $50 \times 50$ \\
\hline & $L_{T 3}\left(=L_{T 4}\right)$ & $20 \times 150$ & $L_{3}\left(=L_{4}\right)$ & $70 \times 70$ \\
\hline & $L_{T 5}\left(=L_{T 6}\right)$ & $30 \times 150$ & $L_{5}\left(=L_{6}\right)$ & $100 \times 100$ \\
\hline & Total TL area & $120 \times 150$ & Total inductor area & $\begin{array}{c}100 \times 100+ \\
140 \times 140+ \\
200 \times 200\end{array}$ \\
\hline & Total mixer area & $180 \times 180$ & Total mixer area & $220 \times 220$ \\
\hline \multirow{4}{*}{$\mathrm{VCO}$} & $L_{T 1}\left(=L_{T 2}\right)$ & $20 \times 150$ & $L_{1}\left(=L_{2}\right)$ & $70 \times 70$ \\
\hline & $L_{1}\left(=L_{2}\right)$ & $70 \times 70$ & $L_{3}\left(=L_{4}\right)$ & $80 \times 80$ \\
\hline & Total TL area & $110 \times 150$ & Total inductor area & $150 \times 150$ \\
\hline & Total VCO area & $160 \times 160$ & Total LNA area & $180 \times 180$ \\
\hline PGA + integrator & Total area & $12 \times 12$ & Total area & $13 \times 13$ \\
\hline Die & Total area & $800 \times 700$ & Total area & $1,500 \times 1,500$ \\
\hline
\end{tabular}

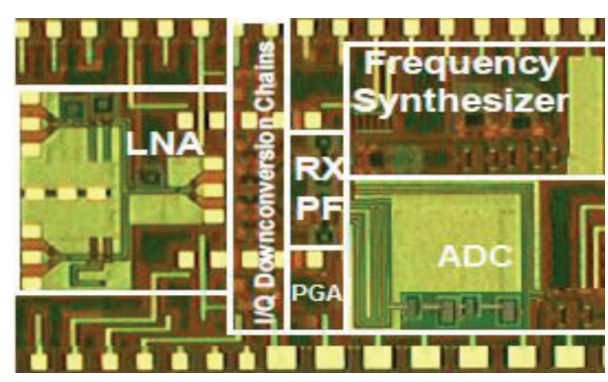

FIgURE 9: Die photograph.

$0.70 \mathrm{~mm}^{2}$ including a large area occupied by the wide ground rings and pads.

\section{Experiment Results and Discussion}

The input and output pads are laid out in GSG configuration with a pitch of $150 \mu \mathrm{m}$ to do wafer level testing for LNA and each block using a probe station with network analyzer. The measurements for LNA have been used here which represent 2-port measurements. The measurements are based on a separate LNA test chip. The power of $-20 \mathrm{dBm}$ is applied from the synthesized sources at both port 1 and port 2. We applied the attenuators of $0 \mathrm{~dB}$ at both port 1 and port 2 . The measured S-Parameter was translated into voltage gain and input impedance.
The radar sensor is tested by probing the input, output, and LO ports. The input, output, and power supply pads are laid out in GPG (ground-power-ground) and GSG (groundsignal-ground) configurations with a pitch of $50 \mu \mathrm{m}$ to perform packaged level testing. The power and ground pads are wire-bonded to the testing board. The S-Parameters at the RF and IF ports are measured using an HP $8722 \mathrm{D}$ vector network analyzer, and the spectrum is obtained using HP 8593A spectrum analyzer.

4.1. Low-Noise Amplifier. Figure 10 shows the input impedance, voltage gain, and noise figure of the LNA for the frequency range of $23 \sim 26 \mathrm{GHz}$. Measurement is obtained using S-Parameter results, and calculation is extracted using (4) to (6) and high-frequency small signal equivalent model. Ideal input impedance of the amplifier must have $45 \sim 50 \Omega$ at the operation frequency. As can be seen in Figure 10, the proposed LNA showed very close results for external equipment measurement as well as the calculation. This LNA also showed good impedance matching with input impedance of $46 \Omega$, high voltage gain of approximately $39 \mathrm{~dB}$, and low-noise figure of $2.86 \mathrm{~dB}$ at the operation frequency of $24 \mathrm{GHz}$.

Table 2 lists comparison results for two different measurement techniques of input impedance $\left(Z_{\text {in }}\right)$, voltage gain $\left(G_{\mathrm{LNA}}\right), N F$ (noise figure), input return loss $\left(R L_{\text {in }}\right)$, and output signal-to-noise ratio $\left(\mathrm{SNR}_{\text {out }}\right)$. Vector network analyzer measures the transmission and reflection characteristics of devices and networks by applying a known swept signal 


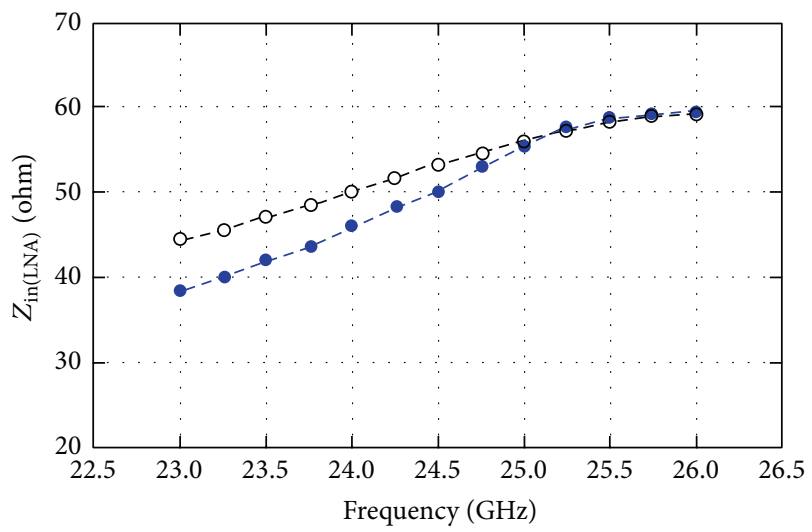

- - Measurement -o- Calculation

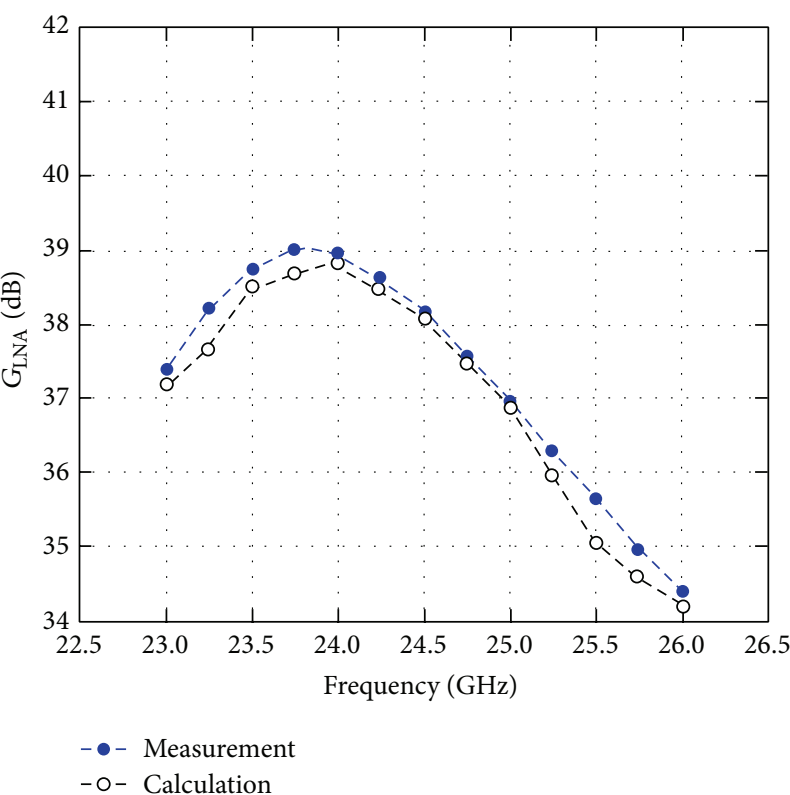

(b)

(a)

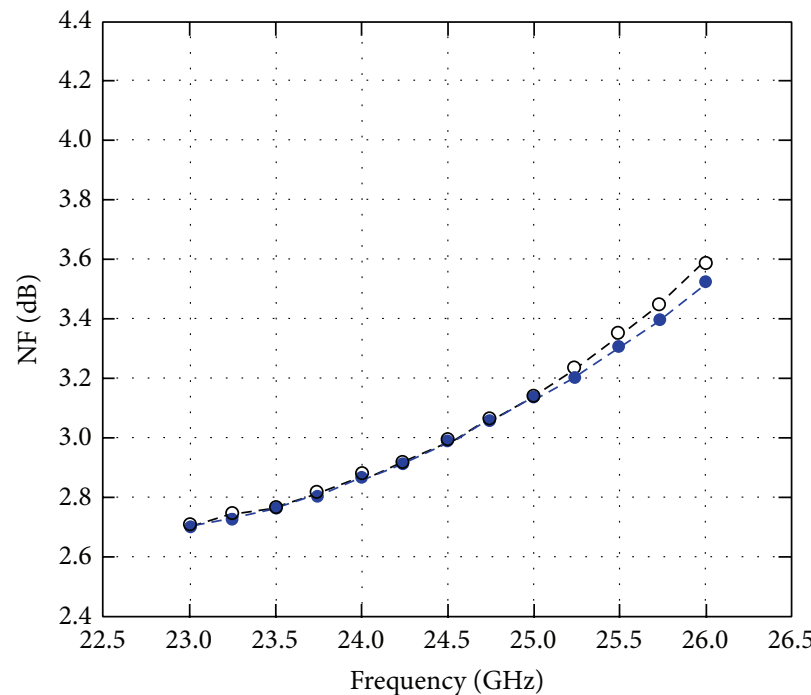

- Measurement

- o- Calculation

(c)

FIGURE 10: Performance results as a function of frequency: (a) input impedance, (b) voltage gain, and (c) noise figure.

from a synthesized source. Device reflection parameters such as reflection coefficient, return loss, VSWR, and complex impedance and transmission parameters such as insertion loss and gain can be measured using the instrumentation. For a good input matching, the LNA must have input impedance of approximate $50 \Omega$. As can be seen in Table 2, the proposed LNA showed very close results in input impedance, gain, noise figure, input return loss, and output signal-to-noise ratio as compared to the calculation. These results verify that the proposed LNA shows very low overall error of less than $5 \%$ for important parameters at the operation frequency range of $23.0 \sim 25.5 \mathrm{GHz}$.
4.2. Downconversion Mixer. Figure 11(a) shows the conversion gain of the downconversion mixer at the output. Figure 11(b) shows the noise figure of the downconversion mixer for the frequency range of $22.5 \mathrm{GHz}$ to $25.5 \mathrm{GHz}$. To provide high conversion gain at the operation frequency, we optimized $W / L$ of $M_{2}$ and $M_{3}$, and we also inserted transmission lines $T_{3}$ and $T_{2}$ as shown in Figure 4. Noise figure measurement is obtained using S-Parameter results, and calculation is extracted using high-frequency small signal equivalent model. As can be expressed in Figure 11, the proposed mixer showed very close results for external equipment measurement as well as the calculation. This 
TABLE 2: Comparison results for two different measurements.

\begin{tabular}{|c|c|c|c|c|c|c|c|}
\hline \multicolumn{2}{|c|}{ Test } & \multicolumn{6}{|c|}{ Frequency [GHz] } \\
\hline & & 23.0 & 23.5 & 24.0 & 24.5 & 25.0 & 25.5 \\
\hline \multirow{5}{*}{ Measurement } & $Z_{\text {in }}[\Omega]$ & 38.5 & 42.2 & 46.0 & 50.1 & 55.2 & 59.4 \\
\hline & $G_{\mathrm{LNA}}[\mathrm{dB}]$ & 37.4 & 38.8 & 39.0 & 38.2 & 36.9 & 35.6 \\
\hline & $\mathrm{NF}[\mathrm{dB}]$ & 2.70 & 2.76 & 2.86 & 3.00 & 3.12 & 3.31 \\
\hline & $\mathrm{RL}_{\mathrm{in}}[\mathrm{dB}]$ & -17.7 & -13.8 & -13.7 & -19.4 & -26.1 & -22.8 \\
\hline & $\mathrm{SNR}_{\text {out }}[\mathrm{dB}]$ & 97.2 & 96.8 & 95.6 & 97.8 & 99.1 & 101.1 \\
\hline \multirow{5}{*}{ Calculation } & $Z_{\text {in }}[\Omega]$ & 44.3 & 47.2 & 50.2 & 53.5 & 56.2 & 58.1 \\
\hline & $G_{\mathrm{LNA}}[\mathrm{dB}]$ & 37.2 & 38.5 & 38.9 & 38.1 & 36.8 & 35.0 \\
\hline & $\mathrm{NF}[\mathrm{dB}]$ & 2.71 & 2.77 & 2.87 & 3.01 & 3.13 & 3.35 \\
\hline & $\mathrm{RL}_{\text {in }}[\mathrm{dB}]$ & -17.7 & -13.8 & -13.9 & -19.5 & -25.9 & -24.5 \\
\hline & $\mathrm{SNR}_{\text {out }}[\mathrm{dB}]$ & 96.8 & 95.6 & 95.5 & 96.7 & 98.8 & 99.9 \\
\hline
\end{tabular}

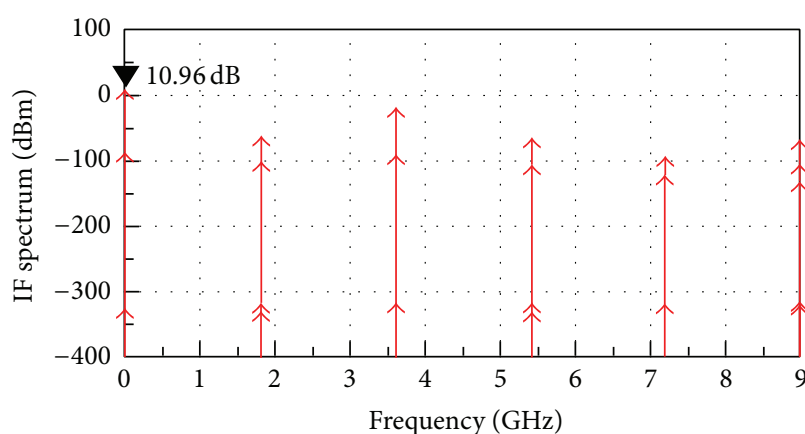

(a)

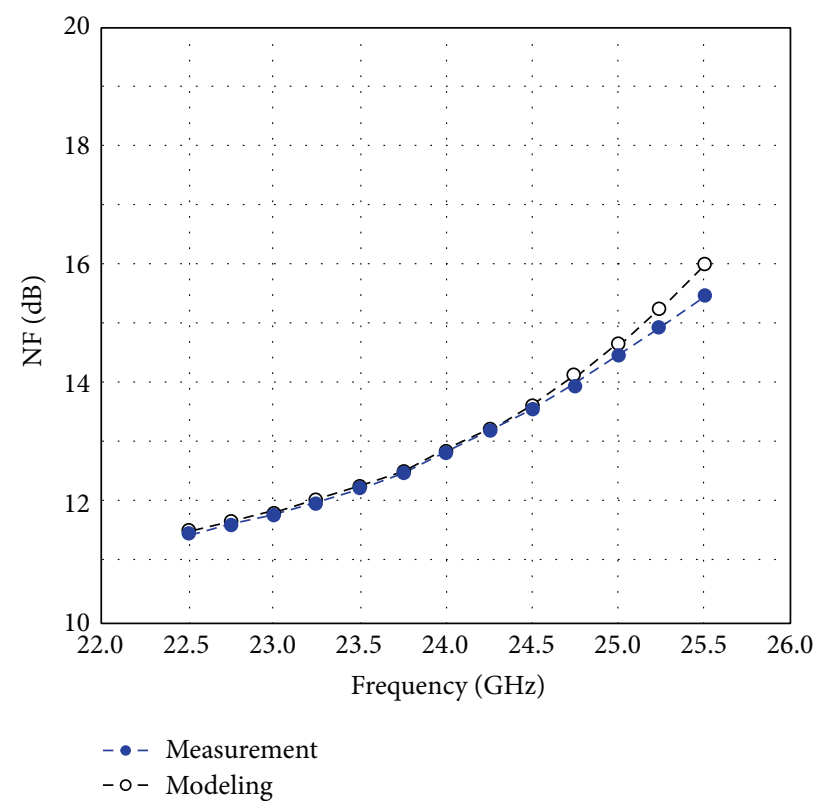

(b)

FIGURE 11: Performance of mixer: (a) conversion gain and (b) noise figure.

mixer also showed excellent noise figure of $12.9 \mathrm{~dB}$ at the operation frequency of $24 \mathrm{GHz}$. The proposed circuit showed the highest conversion gain of $10.96 \mathrm{~dB}$, IIP3 of $7.6 \mathrm{dBm}$, and FoM (figure of merit) of $14.1 \mathrm{~dB}$ and the smallest power consumption of $4.1 \mathrm{~mW}$ and die size of $0.1 \times 0.1 \mathrm{~mm}^{2}$ as compared to recently reported research results. It also showed input return loss of $-43.6 \mathrm{~dB}$ and LO-RF isolation of $-49.2 \mathrm{~dB}$ as compared to conventional research results, respectively.

4.3. Voltage-Controlled Oscillator. The tuning voltage characteristics, transient voltage, Fourier spectrum, and phase noise of the voltage-controlled oscillator are shown in Figure 12. The result of Figure 12(b) is closely related to phase noise. As shown in Figure 12(b), the proposed oscillator showed almost undistorted waveform at the operation frequency of $24 \mathrm{GHz}$. This result verifies that the proposed circuit shows very low phase noise. Several important parameters were also measured for the proposed oscillator. The oscillator showed measurement result of approximately $9 \%$ at the $24 \mathrm{GHz}$ for the FTR (frequency tuning range) and phase noise of approximately $-96 \mathrm{dBc} / \mathrm{Hz}$ at the $1 \mathrm{MHz}$ offset. The $\mathrm{VCO}$ also showed low power dissipation of $5.5 \mathrm{~mW}$ and very small die area of $0.0425 \mathrm{~mm}^{2}$ at the operation frequency as compared to conventional research results.

4.4. PGA (Programmable Gain Amplifier). Figure 13 shows transient voltage for the proposed PGA. It is designed by providing gains of $40 \mathrm{~dB}$ and $60 \mathrm{~dB}$. The results show average values from 10 times' experiments and time variations within less than $2 \%$. These values are measured after 40 nanoseconds' settling time of the PGA to ensure steady-state value. As shown in Figure 13, the proposed PGA showed acceptable values of $40 \mathrm{~dB}$ and $60 \mathrm{~dB}$. 


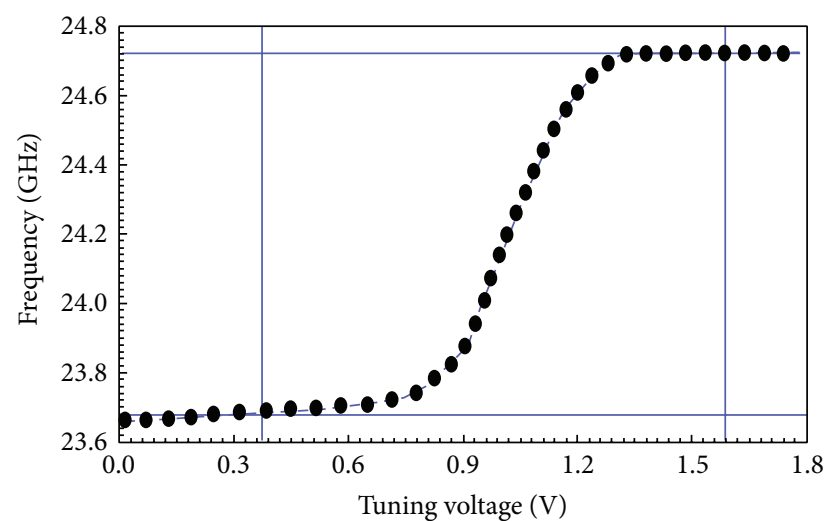

(a)

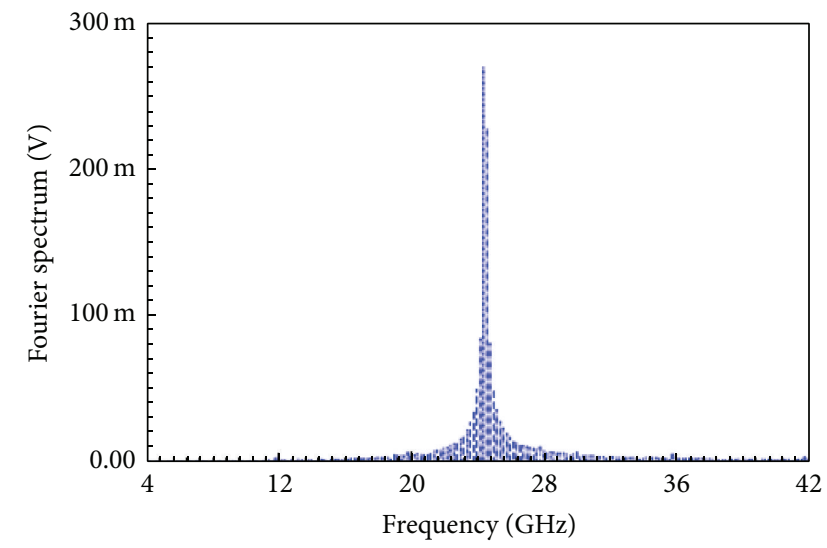

(c)

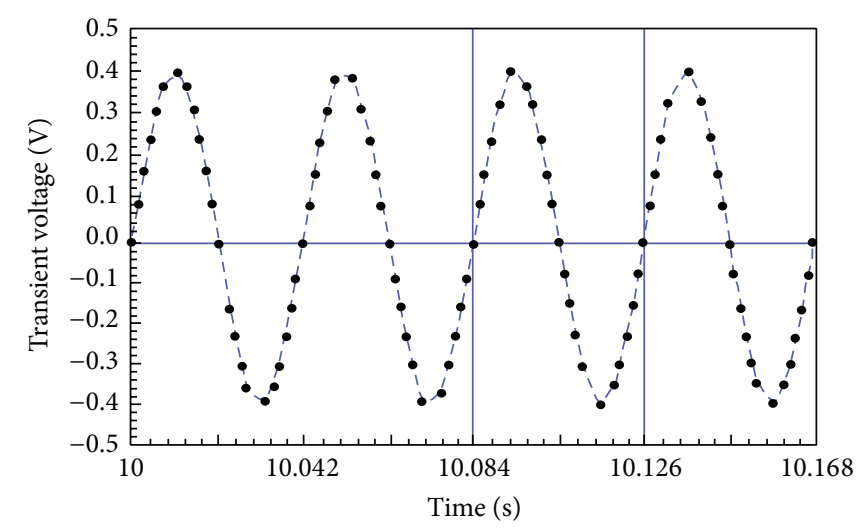

(b)

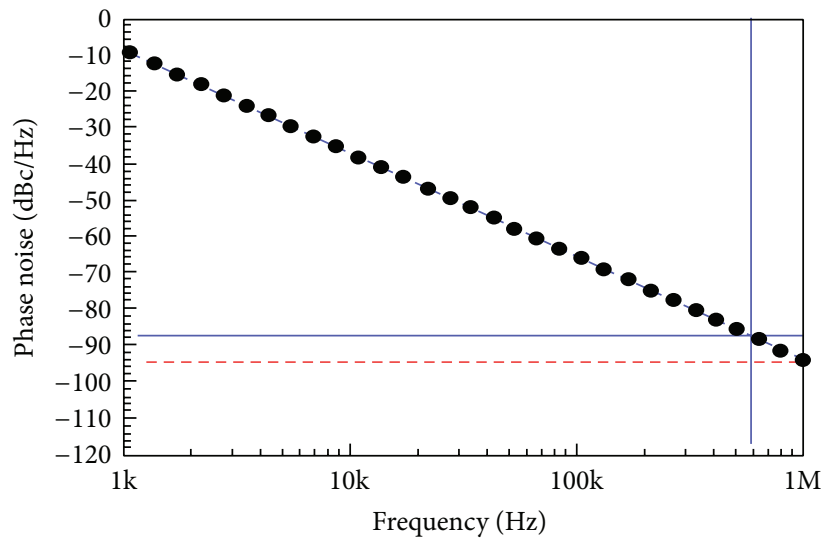

(d)

FIGURE 12: Performance of VCO: (a) tuning voltage characteristics, (b) transient voltage, (c) Fourier spectrum, and (d) phase noise.

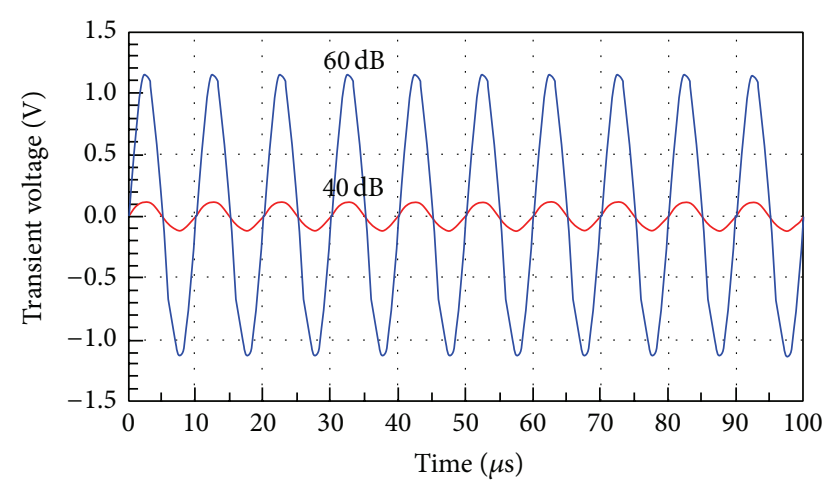

Figure 13: Transient voltage of PGA.

4.5. Radar Sensor. The sensor chip performance is measured using a coaxial setup for $24 \mathrm{GHz}$. In addition to circuit breakouts, in situ probing is also enabled using pads that are absorbed as part of the design. The measured pulse width at the input is chosen for full bandwidth of $7 \mathrm{GHz}$ operation, and the PLL output frequency is set at the center frequency of the $24 \mathrm{GHz}$ band. The $24 \mathrm{GHz}$ output is directly measured on a sampling oscillator. The spectrum corresponding to pulse width of about 300 ps for the $24 \mathrm{GHz}$ pulse is readily measured.
The complete measured performance comparison of the sensor is summarized in Table 3 . The receiver correlation function is determined by varying the delay $R_{x}$ trigger in the pulse generator. Due to the sensor mask constraints at $24 \mathrm{GHz}$, multiple pulses need to be integrated to raise the signal above the noise floor. This is demonstrated in measurement results of Table 3, which shows the integrator output after coherent integration of 200 pulses for each delay setting. A $1 \mathrm{~ns}$ pulse is generated, corresponding to a $12 \mathrm{~cm}$ range resolution, and the delay is varied in 100 ps steps, corresponding to $2 \mathrm{~cm}$ range accuracy. From this comparison, it can be seen that the proposed CMOS receiver compares the state-of-theart realizations and also achieves the lowest noise figure of $2.9 \mathrm{~dB}$ reported so far among the K-band CMOS realizations. The proposed radar sensor showed the very low-noise figure of $2.9 \mathrm{~dB}$ and the highest conversion gain of approximately $40 \mathrm{~dB}$ as compared to recently reported research results as shown in Table 3 . This sensor also showed very small chip area of $0.8 \times 0.7 \mathrm{~mm}^{2}$, low power dissipation of $39.5 \mathrm{~mW}$, and wide operating temperature range of -40 to $+125^{\circ} \mathrm{C}$.

\section{Conclusion}

This paper presented low-noise small-area $24 \mathrm{GHz}$ CMOS radar sensor based on direct-conversion pulsed-radar architecture. The proposed sensor was fabricated using TSMC 
TABLE 3: Performance comparison of $24 \mathrm{GHz}$ radar sensor.

\begin{tabular}{|c|c|c|c|c|c|c|c|}
\hline Performance & This work & {$[10]$} & {$[11]$} & {$[12]^{*}$} & {$[13]^{*}$} & {$[14]$} & {$[15]$} \\
\hline Conversion gain $(\mathrm{dB})$ & 40.2 & 16.5 & 35 & 27.5 & 16 & 31.5 & 37.7 \\
\hline DSB noise figure (dB) & 2.9 & 5.3 & 4.5 & 7.7 & 5 & 6.7 & 5.8 \\
\hline Input return loss $\left(S_{11}\right)(\mathrm{dB})$ & -24.34 & NA & $<-10$ & -21 & NA & -16 & $<-14.5$ \\
\hline Output return loss $\left(S_{22}\right)(\mathrm{dB})$ & -26.28 & NA & $<-15$ & -10 & NA & NA & $<-15$ \\
\hline LO-to-RF leakage (dB) & -40.48 & $<-45$ & $<-70$ & NA & -44 & NA & $<-30$ \\
\hline LO-to-IF leakage (dB) & -38.24 & $<-45$ & $<-38$ & NA & -34.6 & NA & $<-23$ \\
\hline Input $\mathrm{P}_{1 \mathrm{~dB}}(\mathrm{dBm})$ & -30.2 & -26 & -33.2 & -23 & -24.6 & -24 & -20.8 \\
\hline Technology $(\mu \mathrm{m})$ & $0.13 \mathrm{CMOS}$ & $0.13 \mathrm{CMOS}$ & $0.18 \mathrm{BiCMOS}$ & $0.18 \mathrm{CMOS}$ & $0.13 \mathrm{CMOS}$ & $0.065 \mathrm{CMOS}$ & $0.18 \mathrm{CMOS}$ \\
\hline Size $(\mathrm{mm} \times \mathrm{mm})$ & $0.8 \times 0.7$ & $1.4 \times 0.5$ & $3.9 \times 1.9$ & $0.4 \times 0.5$ & $0.86 \times 0.59$ & $1.6 \times 1.2$ & $3.0 \times 1.0$ \\
\hline Power dissipation (mW) & 39.5 & 18 & 107.5 & 64.5 & 22.2 & 78 & 131 \\
\hline Operating temperature $\left({ }^{\circ} \mathrm{C}\right)$ & $-40 \sim 125$ & - & - & - & $-40 \sim 125$ & - & - \\
\hline
\end{tabular}

${ }^{*} \mathrm{LNA}+$ mixer.

$0.13 \mu \mathrm{m}$ RF CMOS technology. To reduce total chip area, transmission lines instead of real bulky inductors were used. The layout techniques for RF were used to reduce parasitic capacitance at the frequency range of $22 \sim 26 \mathrm{GHz}$. The proposed circuit showed the very low-noise figure of $2.9 \mathrm{~dB}$ and the highest conversion gain of approximately $40 \mathrm{~dB}$ as compared to recently reported research results. This sensor also showed very small chip area of $0.56 \mathrm{~mm}^{2}$ and low power dissipation of $39.5 \mathrm{~mW}$. The results were compared in measurement of operating temperature range from -40 to $+125^{\circ} \mathrm{C}$ for practical use in real cars.

\section{Competing Interests}

The authors declare that they have no competing interests.

\section{Acknowledgments}

This research was conducted under the Pukyong National University Research Park (PK-URP) for Industry-Academic Convergence $R \& D$ support program, which is funded by the Busan Metropolitan City, Korea, and this research was supported by Basic Science Research Program through the National Research Foundation of Korea (NRF) funded by the Ministry of Education (2015R1D1A3A01015753).

\section{References}

[1] J.-Y. Ryu, "High-gain low-area power amplifier for $77-\mathrm{GHz}$ automotive radars," International Journal of Applied Engineering Research, vol. 11, no. 2, pp. 934-937, 2016.

[2] J.-Y. Ryu, "Low-power power amplifier for 77-GHz automotive radars," International Journal of Applied Engineering Research, vol. 11, no. 1, pp. 661-663, 2016.

[3] H. Rastegar and J.-Y. Ryu, "A broadband low noise amplifier with built-in linearizer in $0.13 \mu \mathrm{m}$ CMOS process," Microelectronics Journal, vol. 46, no. 8, pp. 698-705, 2015.

[4] S.-G. Kim, H. Rastegar, M. Yoon et al., "High-gain and lowpower power amplifier for $24-\mathrm{GHz}$ automotive radars," International Journal of Smart Home, vol. 9, no. 2, pp. 27-34, 2015.
[5] W.-C. Choi, J.-Y. Ryu, and S. Joung, "Programmable RF built-in self-test circuit for $5 \mathrm{GHz}$ wireless LAN," International Journal of Smart Home, vol. 7, no. 6, pp. 181-190, 2013.

[6] W.-C. Choi and J.-Y. Ryu, "A programmable compensation circuit for system-on-chip application," Journal of Semiconductor Technology and Science, vol. 11, no. 3, pp. 198-206, 2011.

[7] J.-Y. Ryu, S.-W. Kim, D.-H. Lee et al., "Programmable RF system for RF system-on-chip," Communications in Computer and Information Science, vol. 120, no. 1, pp. 311-315, 2010.

[8] J.-Y. Ryu and S.-H. Noh, "A new approach for built-in self-test of 4.5 to $5.5 \mathrm{GHz}$ low-noise amplifiers," ETRI Journal, vol. 28, no. 3, pp. 355-363, 2006.

[9] J. Wenger, "Automotive radar-status and perspectives," in Proceedings of the IEEE Compound Semiconductor Integrated Circuit Symposium (CSIC '05), pp. 21-24, Palm Springs, Calif, USA, November 2005.

[10] V. Subramanian, T. Zhang, and G. Boeck, "Low noise $24 \mathrm{GHz}$ CMOS receiver for FMCW based wireless local positioning," IEEE Microwave and Wireless Components Letters, vol. 21, no. 10, pp. 553-555, 2011.

[11] V. Jain, F. Tzeng, L. Zhou, and P. Heydari, "A single-chip dual-band 22-to-29 GHz/77-to-81GHz BiCMOS transceiver for automotive radars," in Proceedings of the IEEE International Solid-State Circuits Conference (ISSCC '09), pp. 308-309, San Francisco, Calif, USA, February 2009.

[12] X. Guan and A. Hajimiri, "A 24-GHz CMOS front-end," IEEE Journal of Solid-State Circuits, vol. 39, no. 2, pp. 368-373, 2004.

[13] V. Issakov, D. Šiprak, M. Tiebout, A. Thiede, W. Simbürger, and L. Maurer, "Comparison of $24 \mathrm{GHz}$ receiver front-ends using active and passive mixers in CMOS," IET Circuits, Devices \& Systems, vol. 3, no. 6, pp. 340-349, 2009.

[14] A. Mazzanti, M. Sosio, M. Repossi, and F. Svelto, "A $24 \mathrm{GHz}$ subharmonic direct conversion receiver in 65-nm CMOS," IEEE Transactions on Circuits and Systems. I. Regular Papers, vol. 58, no. 1, pp. 88-97, 2011.

[15] V. Jain, S. Sundararaman, and P. Heydari, "A 22-29-GHz UWB pulse-radar receiver front-end in $0.18-\mu \mathrm{m}$ CMOS," IEEE Transactions on Microwave Theory and Techniques, vol. 57, no. 1, pp. 1903-1914, 2009.

[16] L. Mu, T. Xiangqian, S. Ming, and Y. Jun, "Research on key technologies for collision avoidance automotive radar," in Proceedings of the IEEE Intelligent Vehicles Symposium, pp. 233236, Xian, China, June 2009. 
[17] B. Razavi, Design of Analog CMOS Integrated Circuits, McGrawHill, New York, NY, USA, 2001.

[18] B. Razavi, RF Microelectronics, Prentice Hill, New York, NY, USA, 2011.

[19] T. H. Lee, The Design of CMOS Radio-Frequency Integrated Circuits, Cambridge University Press, New York, NY, USA, 2003. 


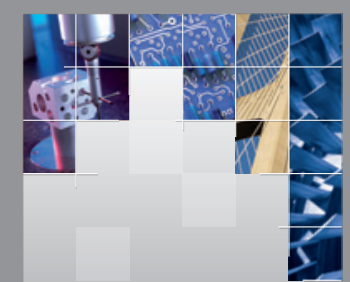

\section{Enfincering}
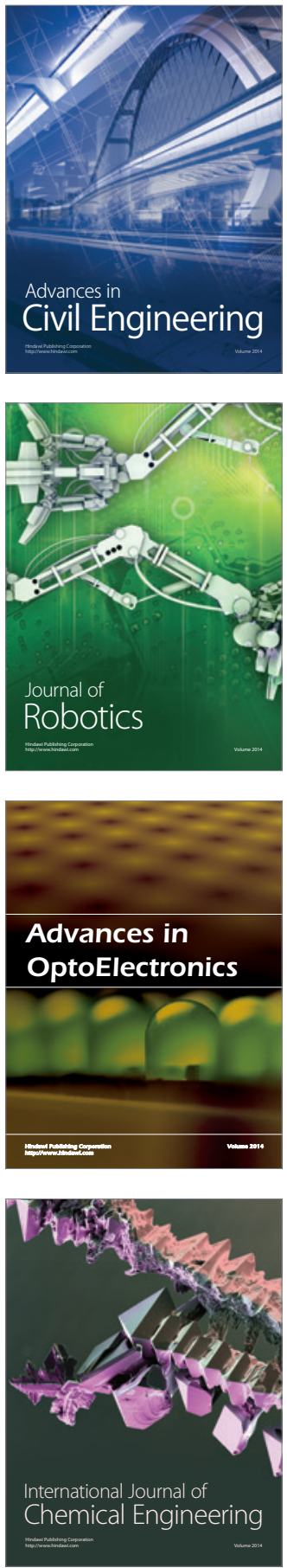

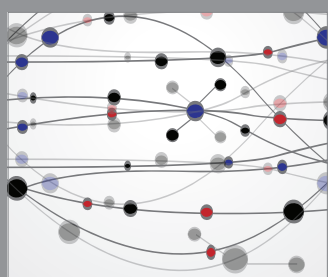

The Scientific World Journal

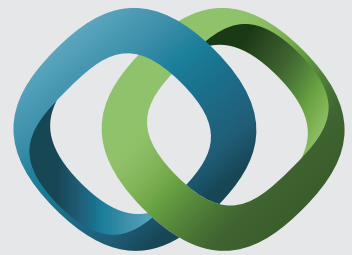

\section{Hindawi}

Submit your manuscripts at

http://www.hindawi.com
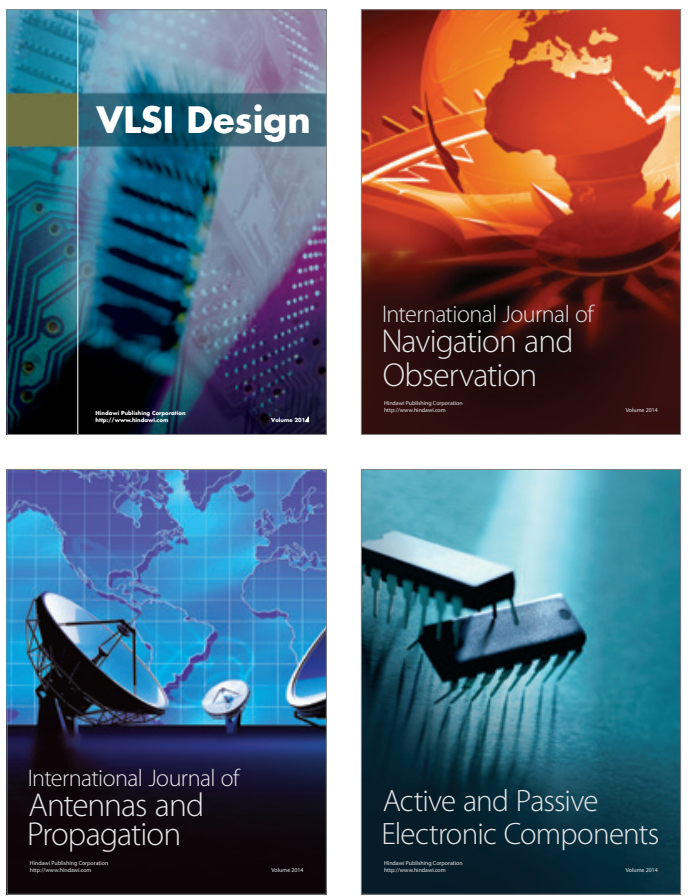
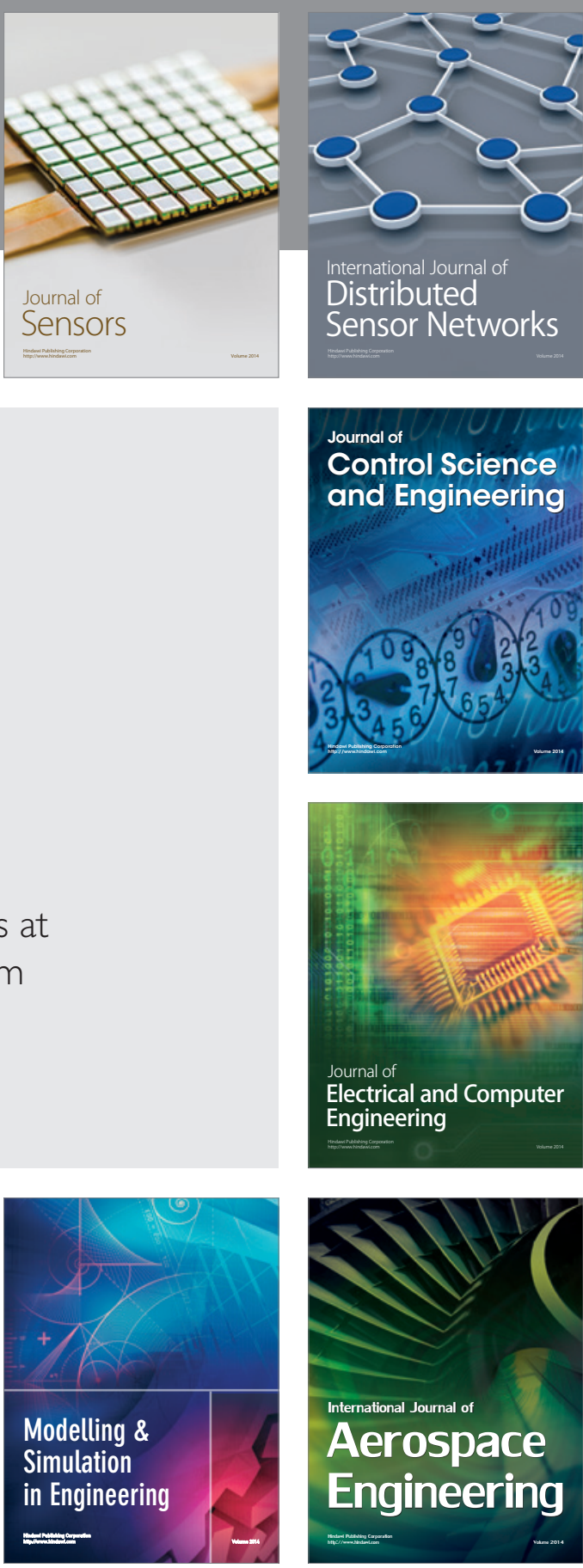

International Journal of

Distributed

Sensor Networks

Journal of

Control Science

and Engineering
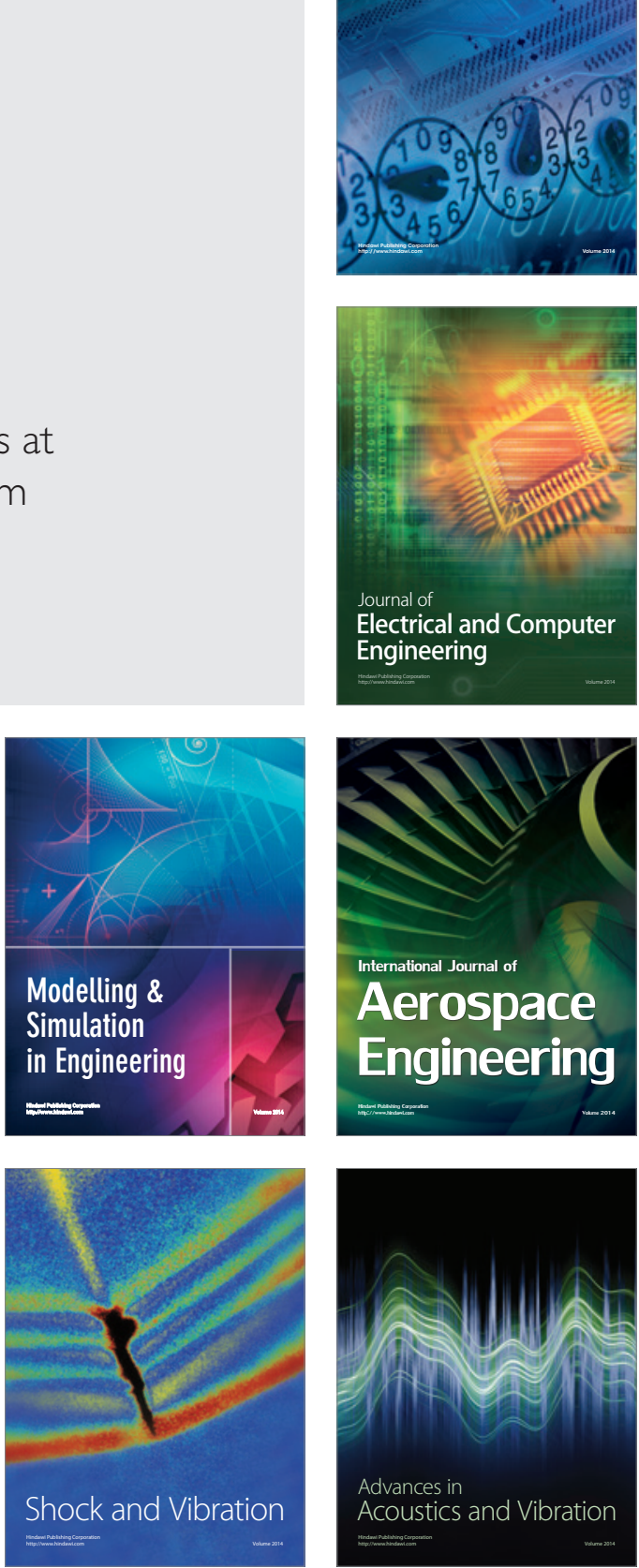